\title{
Menstrual cycle and its relation with Leukocyte count
}

\author{
1. Dr. Sp. Rosemary, ${ }^{2 .}$ Prof. M. Anita Devi, ${ }^{3 .}$ Dr. I. Soniya \\ 1. Post-Graduate Trainee, Department of Physiology, Regional Institute of Medical Sciences, Imphal, Manipur \\ $-795004$ \\ 2. Prof. \& Head, Department of Physiology, Regional Institute of Medical Sciences, Imphal, Manipur - 795004 \\ 3. Post-Graduate Trainee, Department of Physiology, Regional Institute of Medical Sciences, Imphal, Manipur \\ $-795004$
}

\begin{abstract}
Menstrual cycle is the cyclical phenomenon characterized by periodic vaginal bleeding, influencing all the system of the body. The present study was taken up to study the variations in the leukocytes count during different phases of menstrual cycle in $1^{\text {st }}$ professional MBBS students Regional Institute of Medical sciences. 35 healthy female medical students in the age group of 18-28yrs with regular cycles of 28+2days duration participated in the study. Students with irregular cycles, gynaecological disorders, history of prolonged drug intake and history of fever were excluded from the study. Total leukocyte count and differential leukocyte count were examined during menstrual, proliferative and secretory phases during a single cycle. The data collected was statistically analyzed. There was statistically significant increase in total leukocyte count during secretory phase. In differential leukocyte count, there was a significant increase in the neutrophil count during secretory phase, lymphocytes was increased in menstrual and secretory phase, monocyte more on proliferative phase but shows no statistically significance, and eosinophil count, there was not much changes in all three phases. This study was attempted to determine the normal variations in the leukocyte count during the different phases of the menstrual cycle which may help in understanding various disorders.
\end{abstract}

Keywords: Menstrual cycle, leukocytes

\section{Introduction}

Menstrual cycle is a repetitive phenomenon occurring during the reproductive life of a female that involves a patterned sequence of structural, functional, and hormonal system. A normal menstrual cycle lasts from 21 to 35 days with average of 28 days, having 2 to 6 days of flow with average blood loss of 20 to $60 \mathrm{ml}$.The menstrual cycle is under the control of pituitary ovarian axis.

The endometrium is stimulated and regulated by ovarian steroid hormone like estrogen and progesterone which in turn controlled by an integrated hypothalamic pituitary-ovarian axis through the release of follicle stimulating hormone and luteinizing hormone (1). Various authors reported changes of leukocyte count during different phases of menstrual cycle but results have been inconclusive and contradictory. Hence the present study was taken up to study the variations in leukocytes count during different phases of the menstrual cycle.

\section{Materials and Method}

The present study was carried out on 35 healthy female of $1^{\text {st }}$ MBBS students aged between $18-2$ years with normal regular menstrual cycle. The duration of the cycle was $28 \pm 2$ days. Subject with irregular cycles, gynaecological disorders, anemia, history of drug intake affecting menstrual cycle or history of chronic disease and fever at the time of sampling were excluded from the study. Study protocol was explained to the students and informed consent was obtained from each of the student. Experimentation was carried in accordance with ethical standards of the committee according to Helsinki declaration (2). First sample was collected within $48 \mathrm{hrs}$ of onset of menstruation (during menstruation phase), second sample during days $8^{\text {th }}-10^{\text {th }}$ of menstrual cycle (during proliferative phase).Third sample was taken during days $22^{\text {nd }}-24^{\text {th }}$ of menstrual cycle (during secretory phase). All the subjects were followed up during a single cycle. Samples were taken at morning time at 9-10am to avoid diurnal variation. Total leukocyte count were made under Improved Neubauer's chamber using Turk's fluid and differential count by using Leishman's stain under Compound microscope in the Hematology laboratory of department of Physiology, RIMS. The various parameters were statistically analyzed by using SPSS software 16 version, one way ANOVA was used, P value $<0.05$ was considered statistically significant.

\section{Results}

Total leukocyte count was significantly increased in secretory phase as shown in table 1 . Differential Leucocytes count during different phases of menstrual cycle is shown in table no 2 . There was a significant rise 
in Neutrophil percentage during Secretory and menstrual phase compared to proliferative phase. Lymphocyte count was increased in menstrual phase as well as secretory but not statistically significant but reduced during proliferative phase. No significant changes were observed in eosinophil count. Monocyte count was increased in proliferative phase but was not statistically significant.

Table 1. Total leukocyte count during different phases of menstrual cycle.

\begin{tabular}{|l|l|l|l|l|}
\hline No. of subjects (n) & Parameter & Menstrual phase & Proliferative phase & Secretory phase \\
\hline 35 & Total leukocyte count (TLC) & $6616.3 \pm 1.53$ & $6250 \pm 1.13$ & $8600 \pm 1.44^{*}$ \\
\hline
\end{tabular}

All data are expressed as mean $\pm \mathrm{SD}, * \mathrm{P}<0.05$

Table 2. Differential Leucocytes count during different phases of menstrual cycle

\begin{tabular}{|l|l|l|l|}
\hline $\begin{array}{l}\text { Parameters } \\
\text { (Differential Count \%) }\end{array}$ & $\begin{array}{l}\text { Menstrual phase } \\
\left(2^{\text {nd }} \text { day) }\right.\end{array}$ & $\begin{array}{l}\text { Proliferative phase } \\
\left(6^{\text {th }} \text { to } 9^{\text {th }} \text { day }\right)\end{array}$ & $\begin{array}{l}\text { Secretory phase } \\
\left(22^{\text {nd }} \text { to } 24^{\text {th }} \text { day }\right)\end{array}$ \\
\hline Neutrophil \% & $63.8 \pm 3.9$ & $58.8 \pm 4.2$ & $64.73 \pm 4.0^{*}$ \\
\hline Lymphocyte \% & $33.02 \pm 3.04$ & $22.08 \pm 0.28$ & $34.48 \pm 4.74$ \\
\hline Eosinophil \% & $1.57 \pm 0.69$ & $1.31 \pm 0.47$ & $1.40 \pm 0.49$ \\
\hline Monocyte \% & $1.2 \pm 0.40$ & $2.4 \pm 4.26$ & $1.2 \pm 0.40$ \\
\hline Basophil \% & 00 & 00 & 00 \\
\hline
\end{tabular}

All data are expressed as mean $\pm \mathrm{SD}, * \mathrm{P}<0.05$

\section{Discussion}

Menstrual cycle involves a complex and regular changes occurring under the control of hypothalamopituitary ovarian axis (3). Increased in the total leukocyte count was seen in the present study during secretory phase and was statistically significant, which might be due to increase in all the subpopulations of leukocytes. This finding is similar to that observed in studies by Mathur et.al and Tikare et al $(4,5)$. Another study conducted by Rajnee et.al revealed that total leukocyte was increased from menstrual phase to proliferative phase and maximum level occurred around mid cycle. But some other studies showed no change in the number of circulating leukocytes in relation to the menstrual cycle $(1,6)$. In the present study, Neutrophil $(\%)$ was increased in secretory phase which was statistically significant. This probably may be due to the hormonal changes occurring in the ovaries. In vitro studies have suggested that estrogen enhances granulocyte proliferation and probably promotes the release of neutrophil from bone marrow rather than from marginated pool.(7) Progesterone that is secreted by ovaries regulate the neutrophil count(8) The eosinophil (\%) was increased in menstrual phase compare to other phases but was not statistically significant. This result was contrary with other studies where there was a significant drop during mid cycle followed by rise in secretory phase, which occurred in response to physiological stress and increased level of steroid hormone in blood causing eosinopenia (9).

The lymphocyte (\%) was increased in secretory phase but was not statistically significant. This may be probably due to increase in number of Helper T cells, cytotoxic T-cells and natural killer cells, that occur under the influence of steroids but several studies has showed decrease lymphocyte count in secretory phase. The monocyte (\%) was increase in proliferative phase. These may be due to increase in granulocyte and monocyte and due to increased $17 \beta$ estradiol concentration. The basophil count was zero in different phases of the cycle but in other study basophil count decreased in secretory and menstrual phase which was probably due to migration of the cells from the pheriphery blood into the rupturing follicle of ovary and into the ischaemic endometrium (10).

\section{Conclusion}

This study shows changes in Total leukocyte count and differential leukocyte count during the different phases of the menstrual cycle and gives the availability of immune cells in the peripheral blood which may help in understanding various disorders occurring in females.

\section{References}

[1] Rajnee, Vinod KC, Raghuveer C et al. Haematological and electrocardiographic variations during menstrual cycle. Pak J Physiol 2010;6:18-21.

[2] Declaration of Helsinki (1964), 1996. Amended by World Medical Assembly, Venice, Italy. Br Med J 1983; 313:1448-1449.

[3] Sadiqua B, Ashwini S. Study of immune profile during different phases of the menstrual cycle. Int J Biol Med R 2012;3:1407-1409.

[4] Mathur S, Mathur RS, Goust J et al. Cyclic variations in white cell subpopulations in the human menstrual cycle: correlations with progesterone and estradiol. Clin Immun Immunopath. 1979;13:246-253.

[5] Tikare SN, Das KK, Sinha P et al. Blood leucocyte profile in different phases of menstrual cycle. Indian J Physiol Pharmacol 2008;52:201-204. 
[6] Makinoda S, Mikuni M, Sogame M et al. Erythropoietin, granulocyte-colony stimulating factor, interlukin-1 beta and interlukin-6 during the menstrual cycle. IntJ Gyanecol Obstet 1996;55:265-271.

[7] Bain BJ, England JM. Normal hematological values: sex difference in neutrophil count. Br Med J 1975;1:306-309.

[8] Bain BJ, England JM. Variations in leukocyte count during the menstrual cycle. Br Med J 1975;2:473-475.

[9] Pepper H, Linsay S. Levels of platelets, eosinophils, total leucocytes and polymorphonuclear leucocytes during the normal menstrual cycle. J Am Coll Obstet Gyanecol 1959;14:657.

[10] Faas MM, Bouman A, Moes H, Heineman MJ et al. The immune response during the luteal phase of the ovarian cycle: a Th2 response. Fertil Steril 2000;74:1008-1013. 